\title{
WIZARDS AND GENERATORS IN TEACHING INFORMATION TECHNOLOGIES TO STUDENTS OF ENGINEERING
}

\author{
Karol Krol \\ University of Agriculture in Krakow, Poland \\ k.krol@onet.com.pl
}

\begin{abstract}
Websites and web applications are commonly used to disseminate data, which often include a spatial reference. The presentation of such data on websites usually takes a tabular form (i.e. text) or a graphic form for instance, infographics, geo-graphic, interactive charts, diagrams or maps. These presentations are usually created using API frameworks or programming interfaces. At the same time, wizards and generators are developed and shared that allow non-specialized users to create website components. They can be used in the education in the IT field within engineering curricula. The aim of the present work was to conduct a comparative analysis of selected tools that automate the creation of website components in the form of interactive data visualizations, followed by an assessment of their usefulness in teaching the subject of "Information Technologies" within engineering study majors. Selected website generators have been evaluated, which are available in the form of web applications, and the operation of which is based on a graphical user interface. The assessment was made possible via exploratory tests involving the report on the observations made during the creation of model website components. In conclusion, it was shown that website wizards and generators can find application in teaching within the framework of engineering studies, as teaching aids. Students using website wizards and generators not only gain the ability to use specific tools, but they also learn about the many design techniques that accompany these tools. At the same time, the students are becoming familiar with the fieldspecific terminology.
\end{abstract}

Keywords: data visualization, teaching aids, project tools, website components, exploratory tests.

\section{Introduction}

Technological progress, convergence processes, and the development of visual communication are conducive to the formation of new ways of presenting information. Today, data visualization on the Internet is commonly used, and it takes various forms, beginning with static (raster), and ending with dynamic and interactive ones. There is evidence of a growing number of web applications, based largely on visual interactions on the Internet. These applications are directed to users for whom visual experiences are of paramount importance. Users' expectations, information pressure, and natural tendency of people to organize their information environment, lead to seeking ever more and new ways of collecting, processing and presenting data.

Websites and web applications are commonly used to disseminate data, which often include a spatial reference [1]. The presentation of such data on websites usually takes a tabular form (i.e. text) or a graphic form - for instance, infographics, geo-infographics [2], as well as interactive charts, diagrams or maps [3]. These presentations are typically created using API frameworks or programming interfaces. At the same time, website wizards and generators - often available free of charge - also referred to as "visual editors" or "live editors" are developed and shared. These are applications launched in a web browser window, the use of which does not require expert skills. They allow the users to create website components that can be relatively easily implemented within the structure of a hypertext document, thus extending its functionality. These tools are often developed by hobbyists, or by communities of users, but there are also versions created by commercial entities, aimed at promoting their brand, a specific product, or a data source. They can be useful in teaching information and communication technologies in engineering majors that are not directly related to software programming, but where the presentation of data - and spatial data in particular - is of high importance.

\section{Purpose and goals of the research}

There are many internet applications available on the Internet - wizards and generators which allow to create independently various products, e.g. components of websites, maps, charts or whole websites. Some of these tools are recommended by approved international entities from the IT field (e.g., Google or Highsoft). The other ones were created and provided by little known entities, society of users (Open Source) or amateurs. Moreover, these tools are characterized by various ranges of functionality (project possibilities) and availability and also different quality of performance including 
usefulness. Therefore, teachers can have some problems with choosing those, the use of which would benefit both them and the students. The aim of the present work was to conduct a comparative analysis of selected tools that automate the creation of website components in the form of interactive data visualization, followed by an assessment of their usefulness in teaching the subject of "Information Technology" within engineering studies curricula. The comparative analysis and estimation of usefulness in teaching can help teachers choose specific tools.

\section{Information and communication technologies in the education of engineers}

Information and communication technologies (ICT) play an increasingly important role in the functioning of societies. In the twenty-first century, the role of ICT in education is expected to increase even further. There is wide contention that technology use can improve student learning in schools [4]. Both educational researchers and educational organizations have committed to supporting student learning through the effective use of technologies in schools [5-7]. This follows from the fact that infotechnologies have influenced both learning and teaching [8]. At the same time, growing numbers of educational institutions use ICT in teaching, and teach the applications of these technologies. This is related to the adaptation of educational programs to the changing conditions and needs of the labour market; and furthermore, it requires teachers to continually improve their knowledge and skills, and to change their approach towards teaching [9]. However, the use of ICT in education is sometimes limited by barriers that most often result from such factors as underfunding, hardware and software shortages, insufficient teacher knowledge, lack of acceptance of new technologies and lack of motivation to use these technologies in teaching, as well as inequalities in the access to education, and somewhat defective curricula [10].

The use of information technologies in the training of engineers, coupled with technologymediated learning (TML), constitutes a response to the needs of the labour market and results from the expectations of employers [11]. The widespread use of web-based applications, media convergence, and multimedia quality of the message have led to the situation, in which skills that were previously unnecessary are now required by the employees in a variety of jobs. This is often related to the knowledge of industry-specific software products. Furthermore, changes can be observed in the model of communication between citizens and the market, as well as with the state and local administration, resulting from digitization. E-administration and various contents made available via the Internet play an increasingly important role [12]. The demand for education in the field of ICT, and with the application of ICT tools, is also voiced by students themselves, who are eager to use infotechnology and usually demonstrate proficiency in using contemporary tools and devices both in the context of academic and purely entertainment applications [13]. Education within engineering studies should not only enable the students to use field-specific or industry-specific software, but it should also provide them with the competence to use and apply information, the so-called information literacy (IL) [14].

\section{What is the difference between a website wizard and a generator of website components?}

The difference between a website generator and a website wizard results from the way they are used (the manner of operation) and not from the final result they produce, which can be identical in both cases. The functionality of website generators boils down to generating a code, an object or an element, which then requires "embedding" (inserting, or nesting) in the structure of a hypertext document. Generators therefore "produce" ready-made website components, such as, for example, infographics, forms, maps or charts, which need implementation. Website generators are usually operated using the GUI (i.e. graphical user interface). Generating a specific object is preceded with the definition of its attributes and functionality. This is done by filling out forms (entering data), marking checkboxes, and selecting options from drop-down lists.

Website wizards work according to the WYSIWYG (what you see is what you get) principle. Components of websites, such as infographics, animations, as well as entire websites or mobile applications are created in real time by adding or removing (drag and drop) their components graphics, text and other elements. The effects of the work are presented in real time on the display of the device at which the wizard is operated. In both cases, the creation process does not require the user to learn programming skills or to know the markup language. However, such skills may be necessary, at least to a minimum extent, when implementing the component as part of the website. 


\section{Materials and methods}

We have evaluated selected website generators, made available in the form of web applications, the operation of which was based on a graphical user interface (Table 1). Applications for testing were selected based on the criteria of license, functionality (creation of specific objects) and the level of sophistication of the operation. The tools were chosen so as to enable the creation of mapping components or interactive charts by users without programming skills.

The assessment was made possible via exploratory tests, involving the reporting of observations made while using the application to create model website components, according to the previously adopted project assumptions [15]. The practicality of particular applications in teaching the subject of "Information Technologies" was assessed indirectly, through the analysis of their functionality (i.e. designing possibilities they offer).

Table 1

Functionality of the website generators subjected to testing

\begin{tabular}{|c|c|c|}
\hline Generator & Functionality & License \\
\hline $\begin{array}{c}\text { Plotvar: Online } \\
\text { Graph Maker }\end{array}$ & $\begin{array}{c}\text { Wizard of selected types of charts, using } \\
\text { the Highcharts library }\end{array}$ & Free for non-commercial use \\
\hline $\begin{array}{c}\text { amCharts Live } \\
\text { Editor }\end{array}$ & $\begin{array}{c}\text { Wizard of a varied range of charts in } \\
\text { JavaScript technology }\end{array}$ & $\begin{array}{c}\text { Any use, provided that a link to } \\
\text { amCharts service is included }\end{array}$ \\
\hline $\begin{array}{c}\text { Line Graph } \\
\text { Maker }\end{array}$ & Wizard of charts in JavaScript technology & Google APIs Terms of Service \\
\hline Meta-Chart & Wizard of charts, using the Highcharts \\
library & Free for non-commercial use \\
\hline $\begin{array}{c}\text { amCharts Pixel } \\
\text { Map Generator }\end{array}$ & $\begin{array}{c}\text { Map wizard in JavaScript technology, } \\
\text { including maps combined with charts }\end{array}$ & $\begin{array}{c}\text { Any use, provided that a link to } \\
\text { amCharts service is included }\end{array}$ \\
\hline Map Channels & $\begin{array}{c}\text { An application facilitating the } \\
\text { customisation of Google maps }\end{array}$ & Google APIs Terms of Service \\
\hline
\end{tabular}

Source: own study

Two types of website generators were subjected to a comparative analysis - the first, allowing to create "classic" charts and diagrams, such as bar charts or pie charts, and the second, allowing to generate maps, i.e. visualizations of data and objects on the map base. Exploratory tests were performed during the implementation of the project design scenario, which provided for the creation of data visualization constituting a website component, prepared in the format of a bar chart, with the functionality of an interactive data presentation. The second component required the format of an interactive map.

\section{Functionality of website generators - results of development tests}

The Plotvar generator allows you to create line graphs, bar charts, pie charts, and animated graphs (live graphs). During the designing work, a number of program imperfections were identified. One of those was the inability to generate a graph described with the text that would include Polish diacritics. Another disadvantage was the impossibility of putting decimal numbers on the graph. In addition, a problem occurred when describing both axes of the graph at the same time. Plotvar generates charts based on the Highcharts techniques and resources. The advantages of the graphs generated in this manner result follow the advantages of the Highcharts API. The application generates graphs whose component code can be read, written and edited. This allows the user to remove imperfections of the presentation directly in the code.

AmCharts Live Editor is a chart generator that combines the features of a graphical user interface with the current, graphical preview of the changes introduced (i.e. the final result in real time) and the presentation of the code. The advantage of this solution is the possibility of direct intervention in the code, in order to change the parameters of the given graph or the source data. These, in turn, are placed in the data matrix (table) and they form an essential part of the JavaScript code. The charts thus generated are characterized by a high degree of interactivity, combined with smooth animation, gentle shading and rounding, as well as universality. For expert users, an API was made available, which facilitates the creation of advanced data visualizations. 
Line Graph Maker is a typical website generator, which uses the Google Visualization API technology. Charts are generated after configuring the selected attributes of their presentation. During the testing of the generator, it was not possible to download a graph, either in the format of a raster file or as a fragment of the code. Meta-Chart, on the other hand, is an online application that allows you to generate various interactive data graphs in the browser window. The application uses external libraries provided by Highsoft (Highcharts API). Meta-Chart application is accompanied by online advertising, which negatively affects its usability.

The amCharts Pixel Map Generator application facilitates, among other things, the creation of an interactive administrative map of selected regions or countries. The map is created based on configuring its selected parameters. The implementation method of the finished component depends on the format in which it is to be saved (transformation format). The finished map can be saved in a dynamic format (generated by means of a code) or in a static format (as a raster map).

Map Channels is a powerful web application, serving to personalize Google maps. Changing the parameters of the map is carried out by the means of a graphical user interface. The implementation of the map generated in this manner is possible after learning the basic HTML tags and the principle of embedding objects in the floating window of "iframe".

Few of the tested generators made it possible to implement data from external sources, for instance from spreadsheets or KML files (Table 2). This would require the user to know how to prepare a "batch file" in the right format. Such functionality improves the development process of more complex visualizations, while it also requires greater skill from the user.

The usefulness of the website generator in teaching is determined, among other things, by the number of functionalities that the given generator makes available. During the classes, it is advisable to use such tools that would provide various options for editing objects (maps, charts, diagrams) as well as various possibilities of recording the result of the work (in the form of raster, vector or hypertext files). The ability to create the user account, and to save the work result, is the functionality provided by more advanced website generators. This option allows for the implementation of multistage projects that require several classroom sessions.

The presentation of online advertisements on the generator's website calls into question the practicability of its use in the classroom (compare: Meta-Chart). Ad content is often presented in parallel to the user interface, which can be annoying, and which affects the application's performance. Advertisements constitute a kind of "cost", which is accepted by the user, who wants to benefit from the application, the use of which does not require subscription fees.

Table 2

Selected attributes and development potential of the tested website generators

\begin{tabular}{|c|c|c|c|c|c|c|}
\hline $\begin{array}{c}\text { Development } \\
\text { attributes of the } \\
\text { website generators }\end{array}$ & Plotvar & $\begin{array}{c}\text { amCharts } \\
\text { Live Editor }\end{array}$ & $\begin{array}{c}\text { Line } \\
\text { Graph }\end{array}$ & $\begin{array}{c}\text { Meta- } \\
\text { Chart }\end{array}$ & $\begin{array}{c}\text { amCharts } \\
\text { Pixel Map }\end{array}$ & $\begin{array}{c}\text { Map } \\
\text { Channels }\end{array}$ \\
\hline $\begin{array}{c}\text { Implementation of } \\
\text { external data sources }\end{array}$ & - & + & - & - & + & + \\
\hline $\begin{array}{c}\text { Saving working } \\
\text { versions of charts } \\
\text { and/or maps }\end{array}$ & - & + & - & + & + & + \\
\hline $\begin{array}{c}\text { Data presentation in } \\
\text { spatial reference }\end{array}$ & $\mathrm{n} / \mathrm{a}$ & $\mathrm{n} / \mathrm{a}$ & $\mathrm{n} / \mathrm{a}$ & $\mathrm{n} / \mathrm{a}$ & + & + \\
\hline $\begin{array}{c}\text { 3D charts } \\
\text { Animated charts }\end{array}$ & + & + & - & + & $\mathrm{n} / \mathrm{a}$ & $\mathrm{n} / \mathrm{a}$ \\
\hline $\begin{array}{c}\text { Option to use graphics } \\
\text { as the chart's } \\
\text { background }\end{array}$ & - & - & - & + & + & $\mathrm{n} / \mathrm{a}$ \\
\hline $\begin{array}{c}\text { Generating maps with } \\
\text { the presentation of data } \\
\text { in chart format }\end{array}$ & $\mathrm{n} / \mathrm{a}$ & $\mathrm{n} / \mathrm{a}$ & $\mathrm{n} / \mathrm{a}$ & $\mathrm{n} / \mathrm{a}$ & + & $\mathrm{n} / \mathrm{a}$ \\
\hline
\end{tabular}


Table 2 (continued)

\begin{tabular}{|c|c|c|c|c|c|c|}
$\begin{array}{c}\text { Development } \\
\text { attributes of the } \\
\text { website generators }\end{array}$ & Plotvar & $\begin{array}{c}\text { amCharts } \\
\text { Live Editor }\end{array}$ & $\begin{array}{c}\text { Line } \\
\text { Graph }\end{array}$ & $\begin{array}{c}\text { Meta- } \\
\text { Chart }\end{array}$ & $\begin{array}{c}\text { amCharts } \\
\text { Pixel Map }\end{array}$ & $\begin{array}{c}\text { Map } \\
\text { Channels }\end{array}$ \\
\hline $\begin{array}{c}\text { Generating maps with } \\
\text { the presentation of data } \\
\text { in chart format }\end{array}$ & $\mathrm{n} / \mathrm{a}$ & $\mathrm{n} / \mathrm{a}$ & $\mathrm{n} / \mathrm{a}$ & $\mathrm{n} / \mathrm{a}$ & + & - \\
\hline $\begin{array}{l}\text { Generating charts } \\
\text { and/or maps in the } \\
\text { format of: }\end{array}$ & \multicolumn{7}{|l|}{} \\
\hline $\begin{array}{l}\text { - a raster file, } \\
\text { - a vector file, }\end{array}$ & + & + & + & + & + & - \\
\hline- in the code format & - & + & - & + & + & - \\
\hline Online ads & - & - & - & - & + & + \\
\hline
\end{tabular}

Source: own study

When using website generators, the students acquire skills not only in the field of handling specific tools, but they also learn about the many designing techniques that accompany these tools (Table 3). In order to publish online the chart or map that had previously been automatically generated, one needs basic knowledge of the markup language (HTML) or the ability to use a content management system (CMS). Knowledge of publishing website components using the "floating frames" (iframe) can be useful as well. Often this is also related to the working use of HTML editors, "FTP client" software, and will also require the registration of a (free-of-charge) hosting package. This in turn will require the users to familiarize themselves with the market of hosting services, and the range of services available in hosting packages, as well as the rules for registering Internet domains, and many other competencies. These skills (implementation of components, file management in the data cloud, data visualization) may often be useful in everyday work of an engineer. Website wizards and generators are therefore tools that can be used to familiarize the students with infotechnologies at large.

Table 3

Designing/development technologies pertaining to the presentation and implementation of website components in relations to the website generators

\begin{tabular}{|c|c|c|}
\hline $\begin{array}{c}\text { Website generator } \\
\text { Maker }\end{array}$ & $\begin{array}{c}\text { Technology of implementation } \\
\text { JavaScript, Highcharts API, } \\
\text { HTML, CSS }\end{array}$ & $\begin{array}{c}\text { Data entered in the form using GUI, } \\
\text { data array }\end{array}$ \\
\hline amCharts Live Editor & $\begin{array}{c}\text { JavaScript API, amCharts API, } \\
\text { HTML, CSS }\end{array}$ & Data array, CSV \\
\hline Line Graph Maker & $\begin{array}{c}\text { Google Visualization API, } \\
\text { HTML, CSS }\end{array}$ & Google Chart libraries \\
\hline Meta-Chart & Highcharts API, HTML, CSS & Data array \\
\hline PmCharts & $\begin{array}{c}\text { JavaScript API, amCharts API, } \\
\text { HTML, CSS }\end{array}$ & Data array, CSV \\
\hline Map Channels & $\begin{array}{c}\text { JavaScript, HTML, CSS, } \\
\text { Embed a map (iframe), URL }\end{array}$ & $\begin{array}{c}\text { Data array, Google Chart libraries, } \\
\text { KML, CSV or TSV feeds }\end{array}$ \\
\hline
\end{tabular}

Source: own study

\section{Discussion of results and conclusions}

The potential of computer technologies to revolutionize university teaching and learning has long been celebrated by education technologists [16]. Scientific journals in the field of educational technology regularly present research focusing on the ability of technologies like the computer and the Internet to accelerate university students' learning, enhance and democratize access to educational opportunities and support interactivity, interaction, and collaboration. In short, the turn towards 
computer-based teaching and learning is assumed to have revolutionized and revitalized the educational sector $[8,16]$.

New computer tools, technologies and methods are applicable in teaching at various levels of education [17-19], no matter a teaching subject, from nursing [20], through programming [21] and finishing at mathematics [22-23]. Well designed computer-assisted learning can be, however, useful for conceptually difficult topics through use of interactive animations, video, and simulations [24]. Nicholson and Nicholson [25] presented possible using of streaming video transmission as a supportive tool for teaching Microsoft Excel and Access programmes in higher education. They revealed that using a multimedia component increases students' satisfaction from carried out classes, it affects better understanding of the training material and also decreases the amounts of work involved in completing a homework. Nicholson and Nicholson [25] also proved that all this resulted in lessburdened teachers who were spending less time on consulting and explaining the material. Similar advantages can be obtained when using wizards and generators which improve didactic process. Their service is usually intuitive, however, instructional films, which can be also used in education, are available for more advanced tools (e.g., Google Fusion Tables) [26].

Harley and co-authors [21] presented a prototype of a generator that facilitates teaching of programming at university courses and Yip and Kwan [27] noted that more and more video games are applied in teaching. Prensky [28] pointed to the potential of using in education such tools as, among other things: blogs, wikis, the Wikipedia, podcasting, polling devices, peer-topeer (P2P), complex computer and video games, networking, augmented reality, social and community building tools, digital cameras, phone-based cameras/videocams, GPS, speed enhancers and interactive whiteboards. However, he proved at the same time that specific tools, especially computer software, change rapidly. Programmes are replaced by other ones. That requires further training from a teacher.

Infotechnologies are widely used in practice whereby they can make a source of inspiration for new topics of classes and case studies. Bowie and co-authors [29] presented using Google Fusion Tables to create the interactive map of the campus of the Ryerson University in Toronto. This tool allows inexperienced users to develop advanced internet applications. Moreover, Google provides many other tools, e.g. Google Forms that allow to create online surveys and also the wizard of websites Google Sites which allows to create hosted websites (kept) on Google Drive. They are successfully used in education at the academic level from the range of methods and tools that enable interactive visualization of data [30]. In turn, Crampton [31] presented maps' wizards including Google My Maps, an application, which allows to create, display, edition and management of Google maps. Batty and co-authors [32] presented project possibilities of wizards provided within the service Microsoft Bing Maps, and Haklay and Weber [33] - wizards OpenStreetMap. These tools can be successfully used in teaching infotechnology at engineering studies. However, their using needs at least minimum of programmatic knowledge [34].

Classes, where various tools and computer programmes are used, provide students with servicing not only the selected ones. They also develop their general technical skills. Using a big number of generators and wizards is free of charge and does not need expert software, however, it needs from the teachers previous elaborating of study guides (the script of classes). It would involve a significant workload which is one of the barriers to the general use of infotechnology in education [10].

Despite huge efforts to position information and communication technology as a central tenet of university teaching and learning, the fact remains that many university students and faculties make only limited formal academic use of computer technology [16]. Specific character of wizards and generators predisposes them to the role of tools, which can help to change that and particularly in engineering studies.

\section{Advantages of website wizards and generators in teaching the subject of "Information Technologies"}

Website wizards and generators are tools that can provide teaching assistance at the initial stage of educating engineers in the field of software programming, and the use of selected computing techniques and tools. Wizards and generators help develop students" "familiarity" with software. They 
help demonstrate that the user does not have to be only a passive recipient of content, or only use applications shared by other users.

\section{Wizards and generators break the mental barrier faced by users}

In university-level education of engineers, students are often convinced that the creation of interactive visualizations is related to software programming. Many students do not trust their skills in this area; indeed, they may have never had any experience with it, or their experience may have been limited. The use of wizards and generators allows to show them that there exist tools that can improve and automate the process of generating website components, the use of which does not require specialist knowledge. The use of website wizards and generators reduces or eliminates fears of software programming, and helps to break the association between that fear, and the creation of websites and their components. Wizards and generators gently introduce users to the world of software programming, and they open up the meaning of the often hitherto incomprehensible lines of code. In turn, users who have had difficulty understanding the technological complexities, now have a chance to believe in their capabilities and are able to create their first components ever.

\section{Wizards and generators streamline and facilitate the work of the teacher}

Students of engineering faculties, especially those who do not possess special talents in the IT field, are quickly discouraged when working with the code. Coding can be tedious, and the final effect seems distant and vague. This requires the teacher to frequently correct errors and motivate students to work, as well as to remind them about the end result. Not so in the case of website wizards and generators. Wizards seem to be a good fit in the context of the nature of young generations today. Students are prone to being impatient and they tend to expect immediate results. Here the end result is almost at their fingertips, and in the case of wizards, it is taking shape in real time. This encourages students to work, because it is much easier to create objects with specific functionalities out of readymade components than to write many lines of code without having an indication of the final result. Working with website wizards and generators requires less effort from the teacher. It is much easier to explain, for instance, the functions of individual tags (html tags), when the effect they trigger is immediately presented in the generator's window.

\section{Wizards and generators make it possible to familiarize the students with field-specific vocabulary and software}

The use of website wizards and generators allows students to learn about the methods and forms (techniques and tools) of data visualization, but also with online cartography and other field-specific or thematic software. Implementation of components created in an automated manner is often associated with the use of content management systems, as well as registration and operation of the hosting packages. The challenge is not merely to create data visualization using a wizard or a generator. The trick is to actually apply the presentation thus created. Furthermore, along with learning the designing techniques and tools, students become familiar with the terminology of the subject area.

\section{Wizards and generators may sometimes be available for free}

A large number of wizards and generators are made available free of charge. Therefore, students can use them directly in the classroom as well as outside, when doing their homework. Wizards and generators do not require installation on a hard drive; an Internet connection and a web browser will suffice. Website wizards and generators realize specific goals not only for their creators. The growing number of such services results from the expectations of users who are looking for opportunities to create their own thematic reports, and to share them.

\section{Using wizards and generators also has its disadvantages}

Generators and wizards, in addition to numerous advantages, including their simplicity of use and their accessibility, also have certain drawbacks. In this case, creative possibilities are limited by the operational interface. Usually, they allow the user to create a given object in a limited scope. The tools made available free of charge, in addition to the limitations resulting from their functionality, may 
have a number of imperfections (shortcomings, or deficiencies) as well. They can also display intrusive ads that limit their practical performance.

Wizards and generators can be used as a part of introducing students to the world of software programming, of creating various components of websites, online or mobile applications, in particular within engineering study curricula. Their application is justified here due to the technical and design specialization. Parallel to their use, however, coding should also be taught, at least in the basic scope and this chiefly for two reasons. Firstly, the knowledge of the markup language and the basics of software programming allow a better use of the generator's capabilities. Secondly, the user who does not know the basics of software programming, is completely dependent on the functionality of the application. It is also advisable to educate engineers about the possibilities offered by the use of markup languages and programming languages. Only then will the users be able to assess the functionality of the given website generator or a wizard.

\section{Conclusions}

Ultimately, it is the lecturer, who should assess the suitability of ICT information and communication technologies in conducting his or her classes. One of the lecturer's tasks during the preparation of classes is the selection of teaching aids, and suggesting to students that they should use these tools. Lecturers should create conditions for students to acquire the ability to collect, process, analyse and visualize data obtained from various sources, and to support these competencies with specialised, subject-related software. This can be achieved by preparing students to use information technology skills, and then by encouraging them to apply these skills during classes on various subjects.

The curriculum of the subject "Information Technologies" should include as many techniques and tools (and of as varied purposes) as possible, including the use of website generators and wizards, so as to present their designing possibilities to the broadest possible extent. Continuation of education in this field should include learning programming (coding), using selected libraries and programming interfaces (APIs) and frameworks. However, this requires certain special capabilities and talents on the part of the students. In engineering studies, subjects closely related to software programming can therefore be implemented on an optional basis.

\section{Acknowledgements}

The author would like to thank the anonymous referees for their comments on an earlier draft of the paper.

The surveys were financed from the Personal Scholarship Fund for academics of the Hugo Kollataj University of Agriculture in Krakow.

\section{References}

[1] Król K., Szomorova L. The possibilities of using chosen jQuery JavaScript components in creating interactive maps. Geomatics, Landmanagement and Landscape (GLL), Vol. 2, 2015, pp. 45-54. doi: 10.15576/gll/2015.2.45.

[2] He M., Tang X., Huang Y. To visualize spatial data using thematic maps combined with infographics. 19th International Conference on Geoinformatics, June 24-26 Shanghai, China, 2011, pp. 1-5. doi: 10.1109/GeoInformatics.2011.5980880.

[3] Król K., Prus. B. The comparative analysis of selected interactive data presentation techniques on the example of the land use structure in the commune of Tomice. Polish Cartographical Review, Vol. 48(3), 2016, 115-127. doi: 10.1515/pcr-2016-0009.

[4] Polly D., Mims C., Shepherd C. E., Inan F. Evidence of impact: Transforming teacher education with preparing tomorrow's teachers to teach with technology (PT3) grants. Teaching and Teacher Education, Vol. 26(4), 2010, pp. 863-870. doi: https://doi.org/10.1016/j.tate.2009.10.024.

[5] Lawless K. A., Pellegrino J. W. Professional development in integrating technology into teaching and learning: Knowns, unknowns, and ways to pursue better questions and answers. Review of Educational Research, Vol. 77(4), 2007, pp. 575-614. doi: 10.3102/0034654307309921. 
[6] Davis N., Preston C., Sahin I. Training teachers to use new technologies impacts multiple ecologies: Evidence from a national initiative. British journal of educational technology, Vol. 40(5), 2009, pp. 861-878. doi: 10.1111/j.1467-8535.2008.00875.x.

[7] Friedman A., Kajder S. Perceptions of beginning teacher education students regarding educational technology. Journal of Computing in Teacher Education, Vol. 22(4), 2006, pp. 147-151.

[8] Talebian S., Mohammadi H. M., Rezvanfar A. Information and communication technology (ICT) in higher education: advantages, disadvantages, conveniences and limitations of applying elearning to agricultural students in Iran. Procedia-Social and Behavioral Sciences, Vol. 152, 2014, pp. 300-305. doi: 10.1016/j.sbspro.2014.09.199.

[9] Christensen R. Effects of technology integration education on the attitudes of teachers and students. Journal of Research on technology in Education, Vol. 34(4), 2002, pp. 411-433. doi: 10.1080/15391523.2002.10782359.

[10] Sharma R.C. Barriers in using technology for education in developing countries. In: Proceedings of the international conference on information technology: Research and education (ITRE), 2003, pp. 512-516. doi: 10.1109/ITRE.2003.1270670.

[11] Alavi M., Gallupe R. B. Using information technology in learning: Case studies in business and management education programs. Academy of Management Learning \& Education, Vol. 2(2), 2003, pp. 139-153. doi: 10.5465/AMLE.2003.9901667.

[12] Cordella A., Bonina C. M. A public value perspective for ICT enabled public sector reforms: A theoretical reflection. Government information quarterly, Vol. 29(4), 2012, pp. 512-520. doi: 10.1016/j.giq.2012.03.004.

[13] Wilson K. B., Tete-Mensah I., Boateng K. A. Information and communication technology use in higher education: Perspectives from students. European Scientific Journal, Vol. 10(19), 2014, pp. 161-171.

[14]Kong S. C. A curriculum framework for implementing information technology in school education to foster information literacy. Computers \& Education, Vol. 51(1), 2008, pp. 129-141. doi: 10.1016/j.compedu.2007.04.005.

[15] Hellmann T. D., Maurer F. Rule-based exploratory testing of graphical user interfaces. In: International Conference on Agile Methods in Software Development, 2011, pp. 107-116. doi: 10.1109/AGILE.2011.23.

[16] Selwyn N. The use of computer technology in university teaching and learning: a critical perspective. Journal of Computer Assisted Learning, Vol. 23(2), 2007, pp. 83-94. doi: 10.1111/j.1365-2729.2006.00204.x.

[17] Fuller H. L. First teach their teachers: Technology support and computer use in academic subjects. Journal of Research on Computing in Education, Vol. 32(4), 2000, pp. 511-537.

[18] Kerski J. J. The implementation and effectiveness of geographic information systems technology and methods in secondary education. Journal of Geography, Vol. 102(3), 2003, pp. 128-137.

[19] Sung Y. T., Chang K. E., Liu T. C. The effects of integrating mobile devices with teaching and learning on students' learning performance: A meta-analysis and research synthesis. Computers \& Education, Vol. 94, 2016, pp. 252-275.

[20] Jenson C. E., Forsyth D. M. Virtual reality simulation: using three-dimensional technology to teach nursing students. CIN: Computers, Informatics, Nursing, Vol. 30(6), 2012, pp. 312-318.

[21] Harley Z., Harley A. W., Harley E. R. Sharing a wizard for E-learning computer programming. In: e-Learning and e-Technologies in Education (ICEEE), 2013 Second International Conference on (pp. 161-164). doi: 10.1109/ICeLeTE.2013.6644366.

[22] Li Q. Would we teach without technology? A professor's experience of teaching mathematics education incorporating the internet. Educational Research, Vol. 45(1), 2003, pp. 61-77.

[23] Bennison A., Goos M. Learning to teach mathematics with technology: A survey of professional development needs, experiences and impacts. Mathematics Education Research Journal, Vol. 22(1), 2010, pp. 31-56.

[24] Ward J. P., Gordon J., Field M. J., Lehmann H. P. Communication and information technology in medical education. The Lancet, Vol. 357(9258), 2001, pp. 792-796. doi: 10.1016/S01406736(00)04173-8. 
[25] Nicholson J., Nicholson D. B. A stream runs through IT: Using streaming video to teach information technology. Campus-Wide Information Systems, Vol. 27(1), 2010, pp. 17-24. doi: 10.1108/10650741011011255.

[26] Król K., Szewczyk B., Pawłowska B. Interaktywna prezentacja zagadnień środowiskowych za pomocą Google Fusion Tables na przykładzie zdjęć fitosocjologicznych wybranych okolic Tenczynka. Acta Sci. Pol., Formatio Circumiectus, Vol. 15(4), 2016, pp. 253-264.

[27] Yip F. W., Kwan A. C. Online vocabulary games as a tool for teaching and learning English vocabulary. Educational Media International, Vol. 43(3), 2006, pp. 233-249.

[28] Prensky M. How to teach with technology: Keeping both teachers and students comfortable in an era of exponential change. Emerging Technologies for Learning, Vol. 2(4), 2007, pp. 40-46.

[29] Bowie G. D., Millward A. A., Bhagat N. N. Interactive mapping of urban tree benefits using Google Fusion Tables and API technologies. Urban Forestry \& Urban Greening, Vol. 13(4), 2014, pp. 742-755. doi: 10.1016/j.ufug.2014.06.002.

[30]Zhu Y. Introducing Google Chart Tools and Google Maps API in data visualization courses. IEEE Computer Graphics and Applications, Vol. 32(6), pp. 6-9. doi: 10.1109/MCG.2012.114.

[31] Crampton J. W. Cartography: maps 2.0. Progress in Human Geography, Vol. 33(1), 2009, pp. 91 100. doi: 10.1177/0309132508094074.

[32] Batty M., Hudson-Smith A., Milton R., Crooks A. Map mashups, Web 2.0 and the GIS revolution. Annals of GIS, Vol. 16(1), 2010, pp. 1-13. doi: 10.1080/19475681003700831.

[33] Haklay M., Weber P. OpenStreetMap: User-Generated Street Maps. IEEE Pervasive Computing, Vol. 7(4), 2008, pp. 12-18. doi: 10.1109/MPRV.2008.80.

[34] Król K. Creating a static maps of spatial objects using query string parameters - comparative analysis. Acta Sci. Pol., Formatio Circumiectus, Vol. 14(4), 2015, pp. 61-73. 